\title{
Is breakfast consumption related to mental distress and academic performance in adolescents?
}

\section{Lars Lien*}

Institute of General Practice and Community Medicine and Institute of Psychiatry, Frederik Holst Hus University of Oslo, Boks 1072 Blindern, No-03 16 Oslo, Norway

Submitted 14 March 2006: Accepted 25 July 2006

\begin{abstract}
Objective: To examine the relationship between mental distress, academic performance and regular breakfast consumption across gender and immigration status.

Design: Cross-sectional population-based study. Two four-page questionnaires were filled in during two school sessions.

Setting: All junior high schools in Oslo, Norway using the classroom as the setting for the study.

Subjects: All 10th grade students 15-16 years olds in 2000 and 2001. Of 8316 eligible students, 7343 (88.3\%) participated in the study.

Results: All immigrant groups, except the Western countries group, are skipping breakfast more often than Norwegian students, and girls more often than boys (27 versus 19\%). After adjustment for possible confounding factors, the odds ratio (OR) for being mentally distressed when eating breakfast seldom/never compared with every day was $3.0(2.0-4.5)$ for boys, $1.6(1.2-2.1)$ for girls and $1.6(1.5-2.6)$ for the immigrant group. The comparable OR for having low school grades was similar for boys and girls, $2.0(1.3-3.0)$, and $1.6(1.5-2.6)$ for the immigrant groups.

Conclusions: Skipping breakfast is a common feature among 10th grade students. The implications of skipping breakfast on mental distress and academic performance are stronger for boys than girls and stronger for Norwegians compared with immigrants.
\end{abstract}

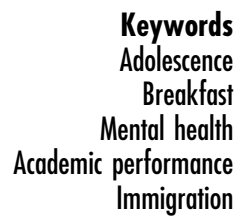

Keywords dolescence performance mmigration
Numerous publications have focused on the association between nutrition and mental health problems, with sugar, micronutrients and omega-3 fatty acids at the centre of attention $^{1-5}$. The effect of dieting, especially among girls, on various mental health problems has also been well documented $^{6,7}$.

The mental health effects of eating meals regularly have received less attention. Smith has published a few studies on the association between mental health problems and eating breakfast regularly ${ }^{8-10}$, and others have examined the effect of daily healthy practices, where eating breakfast is one of them, on mental well-being ${ }^{11-13}$. The conclusion from most of these studies is that eating breakfast regularly is associated with an improved mental health status.

Several explanations have been offered for the relationship between mental health and eating breakfast regularly. According to Smith, breakfast and especially the intake of cereals is beneficial due to its effect on brain glucose after a night-time fast ${ }^{10}$. Regular consumption of breakfast cereals has, in experimental studies, been shown not only to lead to positive mood, but also to improve memory and driving performance ${ }^{10}$.

Regular breakfast consumption has also been linked to reduced stress and reduced infection rates, with a concurrent lowering of cortisol activity ${ }^{14}$. Improved sleep quality and bowel functions have also been related to regular breakfast consumption, both important to mediate psychological well-being ${ }^{10,15}$. The effect of breakfast in reducing fatigue is probably the most important factor contributing to mental health ${ }^{16}$.

Most studies of breakfast and mental health have been on small study samples and with a few exceptions on adults. Chen et al. carried out a prospective study on factors contributing to quality of life in 12- to 13-year-old Japanese children. They found that in addition to physical activity and a normal bedtime, regular breakfast was the most important contributor to quality of life ${ }^{16}$. In a review of dietary habits in adolescents, Bull found that skipping breakfast was related to dieting among girls and that black people skipped breakfast more often than whites, and people from England and Wales had breakfast less often compared with people from Northern and Southern Ireland $^{17}$. A study among Norwegian adolescents from different ethnic groups found a wide variation in food habits and dieting ${ }^{18}$.

Several factors might influence the association between mental distress, school grades and eating breakfast regularly. Parental education is a strong predictor for 
school performance, but less so for mental distress ${ }^{19,20}$. A change in family structure might, however, influence both mental distress and school performance ${ }^{21}$. Socioeconomic status is a strong predictor of both food choice and meal practices ${ }^{22,23}$.

The aim of this study is to examine the association between regular breakfast consumption and mental distress (symptom load) and academic performance (functional impact) of 10th grade students in a multicultural city. Due to the large sample size, we are also able to study if the association differs with regard to gender and immigration status.

\section{Methods}

\section{Participants and subjects}

The study was based on data from the youth part of the Oslo Health Study, a cross-sectional survey conducted by the Norwegian Institute of Public Health, the Municipality of Oslo and the University of Oslo. All pupils in the 10th grade of all schools in Oslo during $1999 / 2000$ and 2000/2001 were included. The 10th grade is compulsory in Norway; therefore, the present study included all 15-16 year olds in two cohorts. Of 8316 eligible pupils, 7343 (88.3\%) participated in the study and each pupil completed two four-page questionnaires. Information about sex was missing for 38 participants because of a data coupling error, and these participants were excluded from the study, leaving 7305 participants.

\section{Dependent variables}

\section{Average grade}

Participants were asked to fill in the most recent grade recorded in their school record book for mathematics, written Norwegian, English and social science. The grade scale is from 1 (lowest) to 6 (highest). An average grade score for each participant was calculated from the four grades. The variable was dichotomised between those with average grade $\leq 3$ and $>3$.

\section{Mental distress}

Internalised problems, such as anxiety and depression, were measured by the 10-item version of Hopkins Symptoms Checklist (HSCL-10). The reliability was high (Cronbach $\alpha=0.87$ ) and the correlation with other instruments, including HSCL-90, has ranged between 0.87 and $0.97^{24-26}$. Each item was rated on a scale of 1 (not at all) to 4 (extremely), with the time period being the past week. An average score for all 10 items of $\geq 1.85$ is a valid predictor for mental distress among subjects aged 16-24 years of age, corresponding to the 1.75 cut-off of HSCL- $25^{26,27}$.

\section{Independent variable}

\section{Having breakfast}

The question asked was: 'How often do you eat breakfast in an ordinary week?' The answering alternatives were seldom/never, 1-2 times per week, 3-4 times per week, 5-6 times per week and daily. In one of the analyses, we dichotomised between those eating seldom ( $\leq 2$ times per week) and often ( $\geq 3$ times).

\section{Control variables}

\section{Educational level of parents}

To obtain information on parental educational level, the questionnaire was linked to sociodemographic information collected by Statistics Norway for all participants. Their unique 11-digit personal identification (ID) number identifies the individuals, and this number was used for the linkage of data files. The data used for research purposes are anonymous because all names and personal ID numbers have been omitted. The following variables were added: Statistics Norway's register of highest parental education completed as at 1 October 2000 (more information at www.ssb.no/english/subjects/05/01/inntind) ${ }^{28}$.

The educational level was, for the purpose of the analysis, grouped into four major groups according to the highest educational level attained: higher university, lower university/college, secondary education and primary or less education.

\section{Family structure}

This variable was self-reported by the pupils. We divided the responses into three groups: living with both parents; living with one parent (comprising those living with only their mother, only their father, or about the same time with either mother or father); and living with foster parents.

\section{Immigrant status}

The majority of the adolescents with immigrant background were born in Norway and were second-generation immigrants. The labelling of participants as immigrant was therefore determined based on their parents' country of birth. Statistics Norway defines immigrants (or ethnic minorities) as those having both parents born in a country other than Norway ${ }^{29}$. This definition was applied in this study.

\section{Smoking}

The possible categories were as follows: no, never; yes, but stopped; yes, at times; and yes, daily.

\section{Dieting}

The question as asked was: 'Have you ever dieted' with these alternatives: no, never; yes, in the past; yes, now; and yes, all the time. 


\section{Soft drinks consumption}

The following question was asked: 'How much do you normally drink of cola/'fizzy' drinks with sugar': seldom/never, 1-6 glasses per week, 1 glass per day, 2-3 glasses per day, 4 glasses or more per day. The variable was dichotomised between those drinking one glass per week or less and those drinking two glasses or more per week.

\section{Data analysis}

Cross tables were analysed with Pearson's $\chi^{2}$ test, and crude odd ratios (ORs) with 95\% confidence intervals (CIs) were calculated. A logistic regression model, with mental distress and school grades as dependent variables, was used to calculate the ORs in the multivariate analysis in separate analyses for gender and immigration status. In addition, interaction analysis between sex, immigration status and the main independent variable was conducted. The level of significance was set to $P \leq 0.05$, at a $95 \%$ CI.

\section{Etbics}

The study protocol was reviewed by the Regional Committee for Medical Research Ethics and approved by the Norwegian Data Inspectorate. The study has been conducted in accordance with the World Medical Association Declaration of Helsinki.

\section{Results}

Eating breakfast is more of a Norwegian and Western countries phenomenon, as significantly more of the immigrants from other continents tend to skip breakfast (Table 1). Only 19\% of boys and $27 \%$ of the girls eat breakfast $\leq 2$ times or less during an ordinary week. There are also significant differences between boys and girls and Norwegians and immigrants in the level of mental distress and the number of those with $\leq 3$ as their average school grade (Table 2).

Parental education and to a lesser degree family structure also seem to influence the regularity of breakfast consumption (Table 1). Only 10\% of students whose parents have a higher university degree eat breakfast seldom, while $38 \%$ of those with only primary education are in the same category. Students who drink sugarcontaining soft drinks, smoke and diet report less frequent breakfast consumption compared with students who drink fewer soft drinks and do not smoke or diet.

\section{Regression analysis}

Before we entered all the proposed variables into the model, we tested the change in OR of the independent variable going from eating breakfast every day as the reference category to seldom/never, on each of the covariates. For mental distress, the largest change was for the dieting variable (OR from 3.2 to 2.2). Smoking gave a change in OR from 3.2 to 2.7. For school grades, parental
Table 1 Prevalence (\%) of those eating breakfast $\leq 2$ times per week by selected sociodemographic variables, soft drinks consumption, smoking and dieting

\begin{tabular}{|c|c|c|c|}
\hline & $n(\%)$ & Prevalence & $P$-value* \\
\hline Gender & & & 0.001 \\
\hline Boys & $3611(49.4)$ & 18.5 & \\
\hline Girls & $3694(50.6)$ & 27.0 & \\
\hline Ethnic groups & & & 0.001 \\
\hline Norway/Western countries & $5463(74.8)$ & 17.3 & \\
\hline Eastern Europe & $174(2.4)$ & 35.8 & \\
\hline Middle East and North Africa & $425(5.8)$ & 36.6 & \\
\hline Sub-Saharan Africa & $192(2.6)$ & 43.1 & \\
\hline Indian subcontinent & $741(10.1)$ & 42.1 & \\
\hline East Asia and Pacific & $188(2.6)$ & 43.8 & \\
\hline Parental educational level & & & 0.001 \\
\hline Higher university & $1271(21.5)$ & 10.3 & \\
\hline Lower university & $1920(32.5)$ & 16.4 & \\
\hline Secondary education & $2330(31.4)$ & 28.4 & \\
\hline Primary education & $395(6.7)$ & 38.0 & \\
\hline Family structure & & & 0.001 \\
\hline Living with both parents & $5418(74.8)$ & 21.0 & \\
\hline Living with one parent & $1712(23.7)$ & 27.6 & \\
\hline Living with foster parents & $106(1.5)$ & 36.3 & \\
\hline Soft drinks consumption & & & 0.001 \\
\hline One glass or less per day & $5748(79.7)$ & 20.2 & \\
\hline Two glass or more per day & $1462(20.3)$ & 33.4 & \\
\hline Smoking & & & 0.001 \\
\hline No, never & $4413(60.7)$ & 18.9 & \\
\hline Yes, but stopped & $681(9.4)$ & 24.9 & \\
\hline Yes, at times & $1161(16.0)$ & 21.5 & \\
\hline Yes, daily & $1014(13.9)$ & 39.8 & \\
\hline Have you ever dieted & & & 0.001 \\
\hline No, never & $4768(65.3)$ & 17.4 & \\
\hline Yes, in the past & $1397(19.1)$ & 28.8 & \\
\hline Yes, now & $628(8.6)$ & 34.9 & \\
\hline Yes, all the time & $440(6.0)$ & 44.2 & \\
\hline
\end{tabular}

${ }^{*} P$-value for the difference between those eating breakfast seldom and often, Pearson's $\chi^{2}$ test.

educational level made the greatest change in OR from 3.4 to 2.5. Smoking changed the OR to 2.8 and drinking soft drinks changed it to 3.0. For the other variables, the changes were small (results not presented in the table).

The strongest correlation between the variables was for average grade and parental educational level, with a Pearson correlation coefficient of $0.22(P=0.001)$.

Table 2 Prevalence (\%) of eating breakfast, mental distress and school grade by gender and immigrant status

\begin{tabular}{|c|c|c|c|c|c|}
\hline & \multicolumn{2}{|c|}{ Gender } & \multicolumn{2}{|c|}{ Immigration status } & \multirow[b]{2}{*}{$N^{*}$} \\
\hline & Boys & Girls & Norwegians & Immigrants & \\
\hline \multicolumn{6}{|l|}{ Eating breakfast $\dagger$} \\
\hline Seldom/never & 8 & 11 & 7 & 17 & 694 \\
\hline 1-2 times a week & 9 & 13 & 9 & 19 & 800 \\
\hline 3-4 times a week & 9 & 10 & 8 & 12 & 667 \\
\hline $5-6$ times a week & 9 & 11 & 10 & 9 & 707 \\
\hline Every day & 66 & 55 & 66 & 44 & 4384 \\
\hline \multicolumn{6}{|l|}{ Mental distress } \\
\hline Yes & 10 & 26 & 17 & 20 & $130 s$ \\
\hline \multicolumn{6}{|l|}{ Grade } \\
\hline Below 3 & 13 & 8 & 8 & 19 & $71 \varepsilon$ \\
\hline
\end{tabular}

*Total number.

†Pearson's $\chi^{2}$ test for differences between groups is $<0.001$, except for mental distress between Norwegians and immigrants $(P=0.009)$. 
The strongest correlation between the independent variables was for soft drinks consumption and smoking, with a Pearson correlation coefficient of $0.18(P=0.001)$. The final evaluation of the model showed a Hosmer and Lemeshow goodness-of-fit test of $P=0.95$.

Boys have higher crude and adjusted ORs for mental distress when skipping breakfast than girls, and Norwegians considerably higher than immigrants (Table 3). For immigrants, it is only when going from eating breakfast every day to seldom/never that remains statistically significant after adjustment. For boys, even going from every day to 3-4 times a week remains significant $(\mathrm{OR}=2.1)$.

With school grades as dependent variable, the gender differences are less prominent for both the crude and adjusted ORs, while the differences between Norwegians and immigrants are immense (Table 4). For the immigrant group none of the adjusted ORs are statistically significant.

\section{Discussion}

The main finding from this study is that eating breakfast regularly is associated with less mental distress and improved academic performance in a dose-response manner among adolescents. Girls and immigrants skip breakfast more often than boys and the Norwegian group, but the association between both mental distress and academic performance is stronger for boys than girls and stronger for the Norwegian compared with the immigrant group even after adjustment for possible confounding factors.

Several studies by Smith have confirmed that eating breakfast regularly improves mental well-being and physical health, and reduces stress in the form of a reduced cortisol level among adults $8,9,14$. Other studies have shown that breakfast is associated with quality of life in schoolchildren ${ }^{16}$, natural killer cell and lymphokine activity in workers ${ }^{13}$ and sleep health in students ${ }^{15}$.

The Norwegian breakfast most often includes some kind of cereal and a drink such as coffee, tea, fruit juice or milk. The frequency of skipping breakfast increases as adolescents become older ${ }^{17}$. In a Norwegian study, 73\% of 15-16 year olds were eating breakfast daily, while only $50 \%$ of 18-19 year olds maintained the same habit $^{30}$. Less is known about the breakfast content of the immigrant groups. Studies has revealed that immigrants from Asia and Africa often consume less fruits and vegetables and more chocolate, sweets and full-fat milk than immigrants from Western countries ${ }^{18}$.

There might be many beneficial effects of breakfast consumption. These include, as pointed out by Smith, the vital energy intake after a long night's fast and the improved bowel function arising from the consumption of cereals ${ }^{10}$. Glucose is essential in the formation of tryptophan, a precursor protein in the synthesis of serotonin, which regulates mood and memory ${ }^{4,31,32}$.

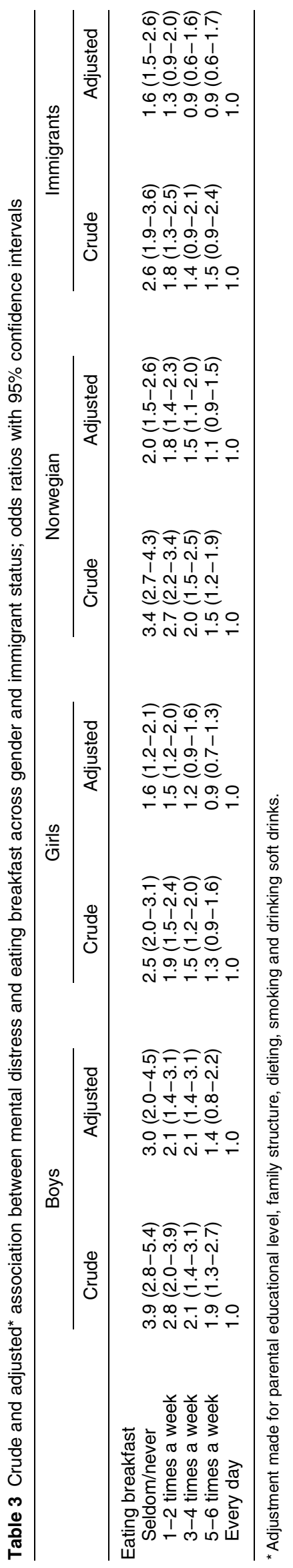


Other positive effects of breakfast might be the consumption of micronutrients and essential fatty acids that in some studies have been shown to be associated with mental health problems such as affective disorders, hyperactivity and behavioural problems $s^{1,2,5,33-36}$.

A different theory on the beneficial effects of regular breakfast eating is that the effect of regularity in life is the most important factor. Adolescents eating breakfast and other meals regularly also tend to have more healthy food habits, drink less alcohol and abstain from smoking ${ }^{12,17,22}$. Finally, the social gathering around a table might also be favourable for mood and of course be an indicator of the functioning of the family that has been shown to be a predictor of distress in adolescents ${ }^{37,38}$.

The strength of this study is the high response rate (88.3\%) from all 15- to 16-year-old adolescents in Oslo for two consecutive years, and the large number of adolescents with an immigrant background (25\%), making selection bias a minor problem. A validated questionnaire was applied to assess mental distress and self-reported grade to assess academic performance. We were able to control for known possible confounders in the multivariate analysis. However, the breakfast questions have not been validated.

There are several limitations in this study. First, we are not able to decide on the direction of the association. It is possible that students who are mentally distressed tend to skip breakfast more often that those who are not, but it is more unlikely that students with lower grades should have a tendency to skip breakfast more often than those with higher grades. Secondly, there might be even more important confounders than those we have already detected, obscuring the association between mental distress, academic performance and regularly eating breakfast.

Thirdly, there might be information bias in the form of misclassifications. There might be responders (personality types) that systematically tend to report negative exposure and the most negative outcome, or positive exposure and the most positive outcome, which may lead to a false inflation or deflation of the association ${ }^{39}$. It is, however, unlikely that, for example, a pupil with a depressive personality should report more frequent skipping of breakfast and lower grades than a non-depressive personality type. One way to minimise the effect of nondifferential, dependent misclassification is to obtain objective information about exposure and/or outcome ${ }^{40}$. In our case, more extensive information about breakfast habits could have been obtained from parents.

The public health impact of our study is that parents should be made more aware of the possible benefit of eating breakfast regularly. With both parents working in busy full-time jobs, it might be difficult to set aside time for breakfast. One possible solution to the time constraint felt by parents and adolescents is to serve breakfast at school, thereby also securing a balanced diet with cereals, fruit and vegetables. 


\section{Acknowledgements}

Sources of funding: The author was employed as a Research fellow by the University of Oslo and did not receive any further funding.

Conflict of interest declaration: The author declares that there are no competing interests.

Acknowledgements: Data collection was conducted as part of the Oslo Health Study 2000-2001 in collaboration with the National Health Screening Service of Norway, now the Norwegian Institute of Public Health.

\section{References}

1 Gesch CB, Hammond SM, Hampson E, Eves A, Crowder MJ. Influence of supplementary vitamins, minerals and essential fatty acids on the antisocial behaviour of young adult prisoners. British Journal of Psychiatry 2002; 181: 22-8.

2 Benton D, Haller J, Fordy J. Vitamin supplementation for 1 year improves mood. Neuropsychobiology 1995; 32: 98-105.

3 Schnoll R, Burshteyn D, Cea-Aravena J. Nutrition in the treatment of attention-deficit hyperactivity disorder: a neglected but important aspect. Applied Psychophysiology and Biofeedback 2003; 28: 63-75.

4 Wallin MS, Rissanen AM. Food and mood: relationship between food, serotonin and affective disorders. Acta Psychiatrica Scandinavica Supplementum 1994; 377: 36-40.

5 Lahey MRS. Diet and its possible role in developmental disorders [online], 2002. Available at www.bamfordlahey.org

6 Lien L, Dalgard F, Heyerdahl S, Thoresen M, Bjertness E. The relationship between age of menarche and mental distress in Norwegian adolescent girls and girls from different immigrant groups in Norway: results from an urban city cross-sectional survey. Social Science \& Medicine 2006; 63: 285-95.

7 Littleton HL, Ollendick T. Negative body image and disordered eating behavior in children and adolescents: what places youth at risk and how can these problems be prevented? Clinical Child and Family Psychology Review 2003; 6: 51-66.

8 Smith AP. Breakfast and mental health. International Journal of Food Sciences and Nutrition 1998; 49: 397-402.

9 Smith AP. Breakfast cereal consumption and subjective reports of health. International Journal of Food Sciences and Nutrition 1999; 50: 445-9.

10 Smith AP. The concept of well-being: relevance to nutrition research. British Journal of Nutrition 2005; 93(Suppl 1): $1-5$.

11 Arai H, Anme T, Katakura N, Sato I. A study on the influence of daily life habits on people's health symptoms (in Japanese). Nippon Koshu Eisei Zasshi - Japanese Journal of Public Health 2003; 50: 435-45.

12 Wetzler HP, Ursano RJ. A positive association between physical health practices and psychological well-being. Journal of Nervous and Mental Disease 1988; 176: 280-3.

13 Morimoto K, Takeshita T, Inoue-Sakurai C, Maruyama S. Lifestyles and mental health status are associated with natural killer cell and lymphokine-activated killer cell activities. Science of the Total Environment 2001; 270: 3-11.

14 Smith AP. Stress, breakfast cereal consumption and cortisol. Nutritional Neuroscience 2002; 5: 141-4

15 Tanaka H, Taira K, Arakawa M, Masuda A, Yamamoto Y, Komoda Y, et al. An examination of sleep health, lifestyle and mental health in junior high school students. Psychiatry and Clinical Neurosciences 2002; 56: 235-6.

16 Chen X, Sekine M, Hamanishi S, Wang H, Gaina A, Yamagami $\mathrm{T}$, et al. Lifestyles and health-related quality of life in Japanese school children: a cross-sectional study. Preventive Medicine 2005; 40: 668-78.

17 Bull NL. Studies of the dietary habits, food consumption and nutrient intakes of adolescents and young adults. World Review of Nutrition and Dietetics 1988; 57: 24-74.

18 Kumar BN, Holmboe-Ottesen G, Lien N, Wandel M. Ethnic differences in body mass index and associated factors of adolescents from minorities in Oslo, Norway: a cross-sectional study. Public Health Nutrition 2004; 7: 999-1008.

19 Costello EJ, Compton SN, Keeler G, Angold A. Relationships between poverty and psychopathology: a natural experiment. Journal of the American Medical Association 2003; 290: 2023-9.

20 Oppedal B. Adolescent mental health in multicultural context. Dissertation, National Institute of Public Health, Oslo, 2003.

21 Gilman SE, Kawachi I, Fitzmaurice GM, Buka SL. Family disruption in childhood and risk of adult depression. American Journal of Psychiatry 2003; 160: 939-46.

22 Johansen A, Rasmussen S, Madsen M. Health behaviour among adolescents in Denmark: influence of school class and individual risk factors. Scandinavian Journal of Public Health 2006; 34: 32-40.

23 Bull NL. Dietary habits, food consumption, and nutrient intake during adolescence. Journal of Adolescent Health 1992; 13: 384-8.

24 Lipman RS, Covi L, Shapiro AK. The Hopkins Symptom Checklist (HSCL) - factors derived from the HSCL-90. Journal of Affective Disorders 1979; 1: 9-24.

25 Sandanger I, Moum T, Ingebrigtsen G, Sorensen T, Dalgard OS, Bruusgaard D. The meaning and significance of caseness: the Hopkins Symptom Checklist-25 and the Composite International Diagnostic Interview. II. Social Psychiatry and Psychiatric Epidemiology 1999; 34: 53-9.

26 Strand BH, Dalgard OS, Tambs K, Rognerud M. Measuring the mental health status of the Norwegian population: a comparison of the instruments SCL-25, SCL-10, SCL-5 and MHI-5 (SF-36). Nordic Journal of Psychiatry 2003; 57: 113-8.

27 Tambs K. Moderate effects of hearing loss on mental health and subjective well-being: results from the Nord-Trondelag Hearing Loss Study. Psychosomatic Medicine 2004; 66: 776-82.

28 Statistics Norway. Den Individbaserte Utdanningsstatistikken [The Individual Based Educational Statistics]. Report No. NOS C645. Oslo: Statistics Norway, 2001.

29 Lie B. Innvandring og innvandrere, 2002 [Immigration and Immigrants 2002]. Oslo: Statistics Norway, 2002.

30 Lien N, Lytle LA, Klepp KI. Stability in consumption of fruit, vegetables, and sugary foods in a cohort from age 14 to age 21. Preventive Medicine 2001; 33: 217-26.

31 Christensen L, Redig C. Effect of meal composition on mood. Behavioural Neuroscience 1993; 107: 346-53.

32 Young SN, Smith SE, Pihl RO, Ervin FR. Tryptophan depletion causes a rapid lowering of mood in normal males. Psychopharmacology 1985; 87: 173-7.

33 Schoenthaler S, Bier ID. The effect of vitamin-mineral supplementation on juvenile delinquency among American schoolchildren: a randomized, double-blind placebo-controlled trial. Journal of Alternative and Complementary Medicine 2000; 6: 7-17.

34 Silvers KM, Scott KM. Fish consumption and self-reported physical and mental health status. Public Health Nutrition 2002; 5: 427-31.

35 Burgess JR, Stevens L, Zhang W, Peck L. Long-chain polyunsaturated fatty acids in children with attention-deficit 
hyperactivity disorder. American Journal of Clinical Nutrition 2000; 71(Suppl): 327-30.

36 Hibbeln JR, Salem N Jr. Dietary polyunsaturated fatty acids and depression: when cholesterol does not satisfy. American Journal of Clinical Nutrition 1995; 62: 1-9.

37 Gilman SE, Kawachi I, Fitzmaurice GM, Buka L. Socioeconomic status, family disruption and residential stability in childhood: relation to onset, recurrence and remission of major depression. Psychological Medicine 2003; 33 $1341-55$
38 Rutter M, Smith D. Psychological Disorders in Young People: Time Trends and Their Causes. New York: Wiley, 1995.

39 Kristensen P. Bias from dependent errors in observational studies (in Norwegian). Tidsskrift for Norsk Laegeforening 2005; 125: 173-5.

40 Podsakoff PM, MacKenzie SB, Lee JY, Podsakoff NP. Common method biases in behavioral research: a critical review of the literature and recommended remedies. Journal of Applied Psychology 2003; 88: 879-903. 